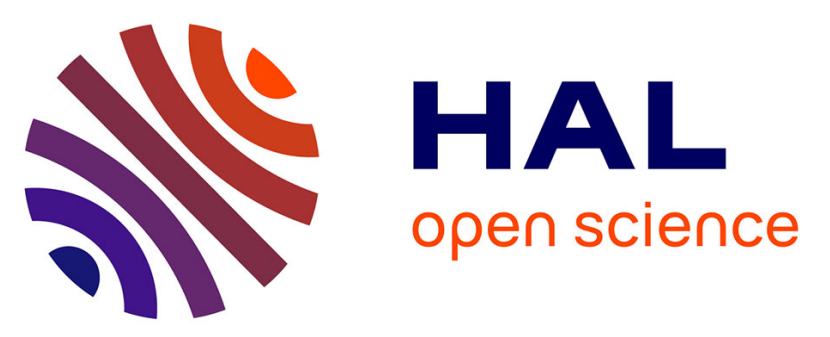

\title{
Where does a glacier end? GPR measurements to identify the limits between the slopes and the real glacier area. Application to the Austre Lovénbreen, Spitsbergen $-79^{\circ} \mathrm{N}$
}

Eric Bernard, Jean-Michel Friedt, Albane Saintenoy, Florian Tolle, Madeleine

Griselin, Christelle Marlin

\section{To cite this version:}

Eric Bernard, Jean-Michel Friedt, Albane Saintenoy, Florian Tolle, Madeleine Griselin, et al.. Where does a glacier end? GPR measurements to identify the limits between the slopes and the real glacier area. Application to the Austre Lovénbreen, Spitsbergen $-79^{\circ} \mathrm{N}$. International Journal of Applied Earth Observation and Geoinformation, 2014, 27 (Part A), pp.100-108. 10.1016/j.jag.2013.07.006 . hal-00831385

\section{HAL Id: hal-00831385 https://hal.science/hal-00831385}

Submitted on 6 Jun 2013

HAL is a multi-disciplinary open access archive for the deposit and dissemination of scientific research documents, whether they are published or not. The documents may come from teaching and research institutions in France or abroad, or from public or private research centers.
L'archive ouverte pluridisciplinaire HAL, est destinée au dépôt et à la diffusion de documents scientifiques de niveau recherche, publiés ou non, émanant des établissements d'enseignement et de recherche français ou étrangers, des laboratoires publics ou privés. 


\title{
Where does a glacier end ? GPR measurements to identify the limits between the slopes and the real glacier area. Application to the Austre Lovénbreen, Spitsbergen
}

\author{
Bernard É. \\ ThéMA, CNRS/Université de Franche-Comté, UMR 6049, Besançon, France \\ Friedt J. M. \\ FEMTO-ST, CNRS/Université de Franche Comté, UMR 6174, Besançon, France \\ Saintenoy A. \\ IDES, CNRS/Université Paris Sud, UMR 8148, Orsay, France \\ Tolle F. \\ ThéMA, CNRS/Université de Franche-Comté, UMR 6049, Besançon, France \\ Griselin M. \\ ThéMA, CNRS/Université de Franche-Comté, UMR 6049, Besançon, France \\ Marlin C. \\ IDES, CNRS/Université Paris Sud, UMR 8148, Orsay, France
}

\begin{abstract}
Glacier limits are usually mapped according to a spatial discrimination based on color of remote sensing images or aerial photography. What appears like ice (white or light colored areas) at the end of the ablation period (end of summer) corresponds to the glacier, while what appears as rock (dark areas) is identified as the slope. This kind of visual discretization seems to be insufficient in the case of small arctic glaciers.

Indeed, the slopes have been described as very unstable parts of glacial basins. Debris are generated by the inclination of the slopes, and reach the glacier surface. Thus, the visible limit does not correspond to the ice extension: a significant amount of ice is potentially covered by rock debris, enlarging the actual glacier surface with respect to the observed area. Hence, we apply Ground Penetrating Radar (GPR) measurements for mapping, beyond the
\end{abstract}


central parts of the glacier, the steep slopes of the Austre Lovénbreen (Spitsbergen, $79^{\circ} \mathrm{N}$ ). The aim is to assess the discrepancy between the limits extracted from remote sensing methods - aerial photography, satellite images and derived digital elevation models - and the GPR data which exhibit significant ice thickness at locations considered outside the glacier itself.

The ice is observed to extend typically from 25 to 30 meters, and up to 100 meters, under the slopes. These measurements allow for a new determination of the rock/ice interface location following criteria beyond the visual and morphological characteristics seen from the surface, as obtained by remote sensing techniques or in-situ observations.

Keywords: Ground penetrating Radar, glacier limit, Arctic, Spitsbergen, polar glacier

\section{Introduction}

Due to a higher ratio between annual mass turnover and total mass, glaciers adapt to changes in climate conditions more rapidly than large ice sheets according to (Dyurgerov and Meier, 2000), yielding continuous boundary change in small ice masses requiring new observations every hydrological season. The most striking morphological indication of glacier dynamics is the front position, visible on historical archives (ground based photographs, aerial photographs, satellite images and field measurements). However, all edges of the glacier react likewise and their position should be considered when assessing glacier evolution.

Remote sensing is classically used to map glacier limits according to a spatial discretization, in which the rock is considered as the hillside and ice-cored moraine, and snow and/or ice is considered as the glacier area in pictures acquired in summer. However, field trips show that this distinction is not so obvious, with the asymptotic case of debris or rock glaciers (Kaufmann and Ladstädter, 2003; Monnier et al., 2009; Kaufmann, 2012; Lugon and Stoffel, 2010) in which the actual glacier extension is unclear. The distinction between ice and its surrounding medium is quite obvious around the accumulation zone of the glacier, thanks to the rimaye path clearly visible at the end of the melting season, even though the latter has been advised to be considered as part of the glacier by (Racoviteanu et al., 2009; Khalsa and Rapp, 2010). However, this distinction becomes blurred below the accumulation area. 
Due to both the instability (landslides, rockfalls, avalanches) of the basin hillsides and the strong slopes, much debris can reach and cover part of the glacier. Furthermore, some of the snow covered slopes might be associated with the glacier. Therefore, the issue lies in the identification of the real glacier limits. The issue of surface feature identification has been extensively considered in (Paul et al., 2013) and will only me reminded here, based on the processing of our own remote sensing datasets, as an introduction of the deeper issue of the relationship between glacier limit derived from features visible from the surface, with respect to sub-surface bedrock topography as derived from geophysical measurements (Bogorodsky et al., 1985).

Within the context of a detailed hydrological and glaciological survey of a small polar glacier (Austre Lovénbreen, Brøgger Peninsula, Svalbard, $79^{\circ} \mathrm{N}$ ), a continuous survey has been carried out from 2006 to 2012 including total glacier volume estimate as derived from a dense network of Ground Penetrating Radar (GPR) measurements (Saintenoy et al., 2013). While processing GPR records to extract the bedrock topography, we observed that the ice thickness systematically remained significant along the expected glacier boundary as identified from remote sensing techniques. Therefore, the geographical question of glacier limits arose: where does the glacier really end ?

\section{Geographical setting and fieldwork}

Svalbard, an archipelago with $60 \%$ glacier cover, represents about $10 \%$ of the total Arctic small glaciers area (Hagen et al., 1993; Liestøl, 1993; Kohler et al., 2007). The Austre Lovénbreen (Fig. 1) is located on the west coast of Spitsbergen (the main island of Svalbard), on the north side of the Brøgger Peninsula $\left(79^{\circ} \mathrm{N}, 12^{\circ} \mathrm{E}\right)$. It is one of the many mountain glaciers found in this area. In a $10.45 \mathrm{~km}^{2}$ basin, Austre Lovénbreen is a small land-based valley and polythermal glacier (Irvine-Fynn et al., 2011) covering an area of $4.6 \mathrm{~km}^{2}$ (in 2009), extending along a $3.6 \mathrm{~km}$ stretch from South to North and $3.2 \mathrm{~km}$ East to West, with

an elevation ranging from 100 to $550 \mathrm{~m}$ a.s.l. Characterized by low-land coastal landscape surrounded by a series of rugged mountain peaks whose elevations reach $876 \mathrm{~m}$ a.s.l (Nobile- 
fjellet), the glacier nowadays covers $43 \%$ of the total basin surface whereas it was occupying about $50 \%$ of the catchment in the 80 s (Hagen et al., 2003).

[Fig. 1 about here.]

As observed on other Arctic regions, nearly all small glaciers are retreating since the end of the Little Ice Age (Hagen et al., 2003; Friedt et al., 2012). Small valley glaciers of the Brøgger Peninsula exhibit an important mass loss (Hambrey et al., 2005).

Glacier area is subject to measurement uncertainties which are here investigated through comparison of limits extracted from remote sensing information (aerial photography and satellite imagery), Digital Elevation Model (DEM) analysis, and subsurface bedrock positioning through GPR measurements.

To determine the glacier limit as defined by the ice thickness reaching a value below the measurement resolution of the GPR, measurements were performed using a Malå Ramac unit fitted with $100 \mathrm{MHz}$ unshielded antennas, generating in ice a wavelet characterized by a wavelength of $100 \mathrm{~cm}$. Although such an operating wavelength is not optimal in terms of depth resolution when operating in the slopes where the bedrock distance to the surface is less than 50 m, it is selected as a tradeoff (Hagen and Sætrang, 1991) between adequate depth resolution and penetration depth of the electromagnetic wave beyond $170 \mathrm{~m}$, the thickest ice region at the center of the glacier ( $\geq 2 \mu$ s two-way travel time, (Saintenoy et al., 2013)).

The measurements were performed on the Austre Lovénbreen during the 3 weeks of a field campaign at the end of April 2011, except for the top-profile of Fig. 5 which was recorded in September 2012 with a visual confirmation of the rock debris-glacier limit. A total of six common-offset profiles were collected, each about $100 \mathrm{~m}$ long, both in accumulation and in ablation areas of the glacier: transect positions in the general context of the glacier as seen in a satellite picture are summarized on Fig. 5. The $100 \mathrm{MHz}$ data were collected in the form of 3542 samples within a time window of $2800 \mathrm{~ns}$, i.e. with a sampling rate of $1261 \mathrm{MHz}$, with trace records triggered by constant time intervals of 0.5 seconds. 8 traces were stacked during the measurement and stored on a personal computer for post-processing. A Globalsat ET312 Coarse/Average (C/A) GPS receiver is connected to a laptop computer used to record 
GPR A-scan traces and the position is recorded once every 5 traces or 2.5 seconds as WGS84 referenced latitude, longitude and altitude.

In this bi-static configuration, the spacing between antennas is $1 \mathrm{~m}$ and was not corrected for in the radargrams presented in this document. Although the altitude information was recorded by the C/A GPS receiver used to tag traces, topography correction was not systematically applied to all radargrams since beyond the angle of the slope, the resulting information is hardly relevant to the current discussion of identifying the bedrock intesection with the surface. The high slope angles nevertheless emphasize the technical challenge of the measurement since the average slope angle is $23^{\circ}$ : beyond the $35^{\circ}$ angle, both rock and snow on the slopes become unstable (André, 1986; André, 1993).

These datasets will provide the raw input for glacier limit definition using sub-surface markers as described in section 4 .

\section{Glacier limit positioning accuracy using remote sensing datasets}

Discussing the glacier limit as observed by different means requires a preliminary assessment of the positioning resolution of the glacier boundaries (Paul et al., 2013). Although the glacier snout provides the most straightforward analysis environment, best accessible when walking along the glacier front while carrying a GPS data logger, it is also least representative of the issue of glacier extension along the slopes. As an initial glacier limit resolution assessment based on the use of datasets acquired through remote sensing techniques, we compare the visual snout limit observed on a summer satellite image, as the boundary between light areas (ice) and dark (rock) regions, with ground based GPS positioning (Fig. 2).

The 2008 GPS measurements were performed at the end of the hydrological year - end of September - while the panchromatic FORMOSAT-2 image was acquired July 31st 2008, providing a dataset with a 2-m resolution (Liu, 2005; Chen et al., 2006). The two trips recording GPS data are separated by several hours and thus have been acquired with different satellite constellation configuration: the difference between the two tracks include field interpretation error and GPS positionning uncertainty, both adding to an error bar of less 
than $5 \mathrm{~m}$. The largest difference between the front position identified by the two methods of $17-\mathrm{m}$ in the area furthest north is attributed to interpretation error due to the rock debris coverage over the ice or retreat between the two dataset acquisition.

Local significant differences are associated with terrain analysis error in rock debris covered areas of the glacier, in which the actual limit is subject to various interpretations. This analysis error might also yield position underestimate during visual interpretation of the images (Fig. 2). Furthermore, the only usable satellite image was acquired in mid-Summer while the GPS tracks were acquired at the end of September: the period of most important retreat separates these two dates and might account for some of the largest discrepencies, since an average retreat rate of $22 \mathrm{~m} \cdot \mathrm{a}^{-1}$ is claimed by (Mingxing et al., 2010). However, the largest differences between the snout position derived from GPS tracks and the one derived from satellite image interpretation (up to $17 \mathrm{~m}$ in the area furthest north) are associated with local terrain analysis error in rock debris covered areas of the glacier.

[Fig. 2 about here.]

An alternative solution, both on the field and when processing DEMs of the glacier, is to define the glacier limit as the slope angle change, from steep slopes to the flat area over the glacier (Paul et al., 2004). This approach avoids the inclusion of avalanches - appearing as light-colored areas even in summer satellite images - as part of the glacier (Fig. 3).

[Fig. 3 about here.]

Satellite images and DEMs have been processed to reach $5 \mathrm{~m} \times 5 \mathrm{~m}$ pixel sampling size: assuming a one pixel resolution in any of the afore-mentioned processing strategies, the most significant positioning accuracy issue is associated with the identification of relevant Ground Control Points (GCP) as needed for geometric corrections (image registration) of the images. The DEM considered throughout this study is a combination of a dataset provided by Norsk Polarinstitutt and acquired in 1995 using stereographic aerial photography, with interpolated dual-frequency GPS tracks acquired in 2009 (Friedt et al., 2012). While significant features are well defined in the moraine area, along the nearby coast and on the 
summits, the glacier itself is a variable surface with hardly any feature which can be identified over multiple datasets. Thus, the resolution of the slopes position is dependent on the availability of nearby geolocated GCPs, and the resulting glacier limit positioning is the sum of the identification resolution and positioning resolution (square root of sum of the variances since both variability sources are independent). While the front position is well defined in areas where the snout is not covered with rock debris, and the upper parts of the glacier are defined by rimayes when visible, most other regions are blurred by avalanche or continuous transitions from glacier to snow covered regions on the slopes in which the rimaye is no longer visible.

[Fig. 4 about here.]

Being confident that the glacier limits are identified within one pixel resolution or $\pm 5 \mathrm{~m}$, and with an accuracy dependent on the limit definition, the remaining issue with the comparison of surface defined limits and the intersection of the bedrock interface as observed by GPR with the surface lies in the fact that the glacier limits have been measured once on a given dataset, while the GPR transects have been performed on another year. Indeed, DEM and satellite imagery are not easily acquired, and our reference dataset is selected from records obtained in 2009. The GPR transects have been acquired in April 2011: the assessment of the glacier limit change within this time interval is needed to compare both glacier limit definitions. One analysis on clear cut rimaye obtained in 1990 and 2010 shows that near the steep slopes, the projected glacier boundary has moved by less than $5 \mathrm{~m}$ (Fig. $4)$.

\section{Glacier limit definition using sub-surface markers}

[Fig. 5 about here.]

Having identified glacier limits using surface features as observed on datasets recorded using remote sensing means (Paul et al., 2013), we now wish to understand how these boundaries relate to those found using sub-surface markers as acquired by GPR. The aim of 
our experiments was to raise the GPR as high as possible on the slopes, starting from a point $A$ on the glacier, and reaching along a path orthogonal to the estimated glacier boundary, a point $B$ on the hillside located close to a rock layer visible above the snow cover (Fig. 6). Mountaineering techniques were used to hang and hoist the GPR: a belay anchor was installed and a rope was used to move the overall device. The two operators also tried to pull the device while keeping a regular walking pace, although GPS coordinates of traces were periodically recorded. On the field, the objective was to determine where and when the ice signal disappears on the collected traces. The challenge of this measurement setup lies in the steep slopes, $>30^{\circ}$ steep, along which the GPR was tracked. In addition, the quality of snowpack made of fresh snow exhibiting little cohesion made the anchoring unstable.

[Fig. 6 about here.]

The post-processing steps are limited to re-sampling the space interval of the traces by considering the total track length using the GPS coordinates, selecting a constant space interval equal to the total length divided by the number of traces, and assigning each trace closest to the equidistant spacing in the final radargram. No migration was performed as it was not needed in the context of seeing the limit of the glacier on the radargram, nor the slope of the ice/bedrock interface. Zero-time correction was performed by removing a common time offset to all traces for the direct electromagnetic wave from emitter to receiver to be located at the time origin of all A-scans. The conversion from echo reception time to depth is obtained by using an electromagnetic velocity in ice of $170 \mathrm{~m} / \mu$ s deduced from a relative permittivity of ice of 3.1 as found for dry, cold ice (Hagen and Sætrang, 1991; Saintenoy et al., 2013).

\section{Results and discussion}

An initial qualitative interpretation of the radargrams (Fig. 7) is obtained by visually identifying the junction of the ice-rock interface with the surface. This feature is most striking as a continuous interface hardly disturbed by point-like reflectors such as bedieres, 
crevasses or rocks buried in the ice. The ice-rock interface intersection with the surface will be used to define the glacier limit.

[Fig. 7 about here.]

For each transect, two positions defined as the glacier limit as identified from sub-surface features are selected: on the one hand the abscissa at which the echo signal extrapolating the bedrock interface slope to the zero-time GPR traces defined as the surface. Hence, two solid vertical lines define these two markers of the true limit of the glacier as shown on Fig. 7 (solid lines) and are compared with the limit defined from surface features observed on remote sensing datasets on a zenital projected map (dashed lines).

We observed a gap typically ranging between 20 and $40 \mathrm{~m}$ - with a maximum value of $97 \mathrm{~m}$ and a minimum value of $11 \mathrm{~m}$ - for each transect between the limit given by image interpretation and the limit given by the radargram. The maximum value of $97 \mathrm{~m}$ is on the north-eastern transect at the base of the Haavimb mountain.

The main result is that the ice extends beyond the limits usually mapped for glaciers. However, the dynamic connection between ice and the glacier itself is unclear: while a rimaye would undoubtly demonstrate that both ice masses (below the slopes and the main glacier) are dynamically disconnected, no such a feature was visible on the radargrams while crevasses are otherwise clearly visible. The only discontinuity clearly visible on one of the radagrams is a deep bediere whose extension to the bedrock is not visible (Fig. 7, trace 3).

By combining field observations (Fig. 8) and radar measurements, we can state that the lower parts of the slopes are filled with ice covered by rock fallen from the upper parts of the slopes, and this ice is connected to the main glacier (Fig. 9). An example of this process is illustrated on the bottom-right picture of the Haavimb mountain, visible on the foreground of Fig. 8, in which multiple accumulation layers of rock debris fallen from the slopes are visible over the ice, while some of the ice connected to the glacier is still visible on the lower part of the slopes. This is visible on multiple other spots around the glacier thanks to the strong melt rate of the last years. It demonstrates a significant interpretation difference compared to a traditional image analysis. The glacier limit position becomes a major source 
of uncertainty in the error budget since the position discrepency between remote sensing surface feature based limit identification and sub-surface bedrock interface intersection with the surface is much larger than the previously estimated \pm 1 pixel uncertainty (Saintenoy et al., 2013).

[Fig. 8 about here.]

Assuming an error on the glacier limit position of $30 \mathrm{~m}$ along the $14.1 \mathrm{~km}$ boundary, then the area uncertainty with respect to the total $4.6 \mathrm{~km}^{2}$ is $0.42 \mathrm{~km}^{2}$ or $10 \%$. This area uncertainty yields a significant contribution in the global mass budget of a glacier when computing the interpolated ablation stake height measurement mutliplied by the glacier area, although the remote sensing-based surface feature definition of the limits will always underestimate the actual glacier area and only bias the result. Notice furthermore that this glacier limit definition yields a much larger uncertainty than those cited in (Paul et al., 2013) in which glacier delineation by multiple authors yield an average area standard deviation of 2.6 (Ötzel Alps) to $5.7 \%$ (Alaska) depending on the geographical settings.

However, the contribution of the varying limit definitions to the glacier volume is less significant since the glacier is shallowest in these regions: assuming a $45^{\circ}$ slope, the $30 \mathrm{~m}$ limit position uncertainty yields a maximum depth uncertainty of $30 \mathrm{~m}$ as well, contributing to a volume of $0.0063 \mathrm{~km}^{3}$ or $1.8 \%$ of the $0.3487 \mathrm{~km}^{3}$ glacier volume derived from GPR measurements (Saintenoy et al., 2013). Although our previous analysis attributed the main source of uncertainty to the bedrock interpolation error as observed by computing the kriging variance, this statistical estimator is known to overestimate the actual interpolation error (Chainey and Stuart, 1998; Journel, 1986; Rotschky et al., 2007; Serra, 1987) due to its sensitivity solely to measurement point position and not to the actual ice thickness values. However, with a tenfold contribution to the ice volume uncertainty with respect to the next error source (ice thickness derivation, consistent with previous estimates (Hagen and Sætrang, 1991), the interpolation error remains significant even for such a high trace density as described in (Saintenoy et al., 2013). 
Finally, the $1.8 \%$ volume contribution represented by ice under slopes debris raise other questions. First of all, this result highlights the uncertainty of the hydrological contribution of the glacier, especially during high melting events, since we are unable to assess the hydrological connectivity between the main drainage system and the slopes. Furthermore, the question of the dynamic connection between this ice buried under the slopes and the main glacier flow remains open Scherler et al. (2011). The outstanding issue concerning future dynamics is also crucial to determine if the ice below the debris (now protected) will evolve in the same way as the ice free of debris, more vulnerable to melting Vieli et al. (2002); Hagen et al. (2003).

[Fig. 9 about here.]

\section{Conclusion}

In addition to assessing the glacier limit uncertainty when derived from surface features observed on datasets acquired through remote sensing mesurements, we consider the consistency of this classical approach with the glacier boundary defined as the intersection of the bedrock interface with the surface as derived from sub-surface Ground Penetrating Radar measurements.

While the ice thickness remains significant $(\geq 20 \mathrm{~m})$ at the visually identified glacier boundary, the glacier is observed to extend well beyond the slopes, at a distance of 20 to

$40 \mathrm{~m}$ below the rock cover visually defining the glacier limit. On the small glacier considered in this study, the uncertainty on the definition of the limit yields a $10 \%$ uncertainty on the glacier area, a significant source of error when computing mass balance. On the other hand, the contribution to the glacier volume is of the same order of magnitude than the ice thickness uncertainty derived from GPR measurements. The dynamic connection of this ice mass to the main glacier remains an open question. 


\section{Acknowledgements}

Funding for this research activity was provided by the French National Research Agency (ANR) Hydro-Sensors-FlOWS program, IPY \#16 program, and IPEV. J. Kohler (Norwegian Polar Institute, Norway) kindly provided the 1995 DEM.

\section{References}

André, M.-F., 1986. Dating slope deposits and estimating rates of rock wall retreat in NW Spitsbergen by lichenometry. Geografiska Annaler, Series A, Physical Geography 58 (1-2), $65-75$.

André, M.-F., 1993. Les versants du Spitsberg, approche géographique des paysages polaires. Presses Universitaires de Nancy.

Bogorodsky, V., Bentley, C., Gudmandsen, P., 1985. Radioglaciology. Springer.

Chainey, S., Stuart, N., 1998. Stochastic simulation: an alternative interpolation technique for digital geographic information. Taylor \& Francis Ltd, pp. 3-24.

Chen, L.-C., Teo, T.-A., Liu, C.-L., May 2006. The geometrical comparisons of RSM and RFM for FORMOSAT-2 satellite images. Photogrammetric Engineering \& Remote Sensing $72(5), 573-579$.

Dyurgerov, M., Meier, M., February 15 2000. Twentieth century climate change: Evidence from small glaciers. Proceedings of the National Acadamedy of Sciences (PNAS) 97 (4), $1406-1411$.

Friedt, J.-M., Tolle, F., Bernard, E., Griselin, M., Laffly, D., Marlin, C., 2012. Assessing the relevance of digital elevation models to evaluate glacier mass balance: application to Austre Lovénbreen (Spitsbergen, $\left.79^{\circ} \mathrm{N}\right)$. Polar Record 48 (244), 2-10.

Hagen, J. O., Kohler, J., Melvold, K., Winther, J.-G., 2003. Glaciers in Svalbard: mass balance, runoff and freshwater flux. Polar Research 22, 145-159. 
Hagen, J. O., Liestøl, O., Roland, E., Jørgensen, T., 1993. Glacier Atlas of Svalbard and Jan Mayen. Vol. Meddelelser nr. 129. Norsk Polarinstitutt.

Hagen, J. O., Sætrang, A., 1991. Radio-echo soundings of sub-polar glaciers with lowfrequency radar. Polar Research 9 (1), 99-107.

Hambrey, M., Murray, T., Glasser, N., Hubbard, A., Hubbard, B., Stuart, G., Hansen, S., 2005. Structure and changing dynamics of a polythermal valley glacier on a centennial time-scale: Midre Lovénbreen, Svalbard. Journal of Geophysical Research 110.

Irvine-Fynn, T., Hodson, A., Moorman, B. J., Vatne, G., Hubbard, A. L., 2011. Polythermal glacier hydrology: A review. Rev. Geophys. 49, RG4002.

Journel, A., 1986. Geostatistics: Models and tools for the earth sciences. Mathematical Geology 18 (1), 119-140.

Kaufmann, V., 2012. Detection and quantification of rock glacier creep using high-resolution orthoimages of virtual globes. In: International Archives of the Photogrammetry, Remote Sensing and Spatial Information Sciences. Vol. 39-B5. XXII ISPRS Congress, Melbourne, Australia, pp. 517-522.

Kaufmann, V., Ladstädter, R., 2003. Permafrost. Swets \& Zeitlinger, Lisse, the Netherlands, Ch. Quantitative analysis of rock glacier creep by means of digital photogrammetry using multi-temporal aerial photographs: two case studies in the Austrian Alps.

Khalsa, S., Rapp, B., May 2010. GLIMS analysis tutorial, www.glims.org/apsAndDocs/ assets/GLIMS_Analysis_Tutorial_a4.pdf.

Kohler, J., James, T. D., Murray, T., Nuth, C., Brandt, O., Barrand, N. E., Aas, H. F., Luckman, A., 2007. Acceleration in thinning rate on Western Svalbard glaciers. Geophysical Research Letters 34, 1-5.

Liestøl, O., 1993. Glaciers of Europe in Satellite image atlas of glaciers of the world. USGS, Ch. Glaciers of Svalbard, Norway, pp. 127-151. 
Liu, C.-C., 2005. Processing of FORMOSAT-2 imagery for site surveillance. In: 26th Asian Conf. on Remote Sensing. Hanoi, Vietnam.

Lugon, R., Stoffel, M., 2010. Rock-glacier dynamics and magnitudefrequency relations of debris flows in a high-elevation watershed: Ritigraben, Swiss Alps. Global and Planetary Change 73, 202-210.

Mingxing, X., Ming, Y., Jiawen, R., Songtao, A., Jiancheng, K., Dongchen, E., 2010. Surface mass balance and ice flow of the glaciers Austre Lovénbreen and Pedersenbreen, Svalbard, Arctic. Chinese journal of polar science 21 (2), 147-159.

Monnier, S., Camerlynck, C., Rejiba, F., 2009. Ground-penetrating radar surveys on rock glaciers in the Vanoise Massif (Northern French Alps): methodological issues. Géomorphologie : relief, processus, environnement 2, 129-140.

Paul, F., Barrand, N., Baumann, S., Berthier, E., Bolch, T., Casey, K., Frey, H., Joshi, S., Konovalov, V., Bris, R. L., Mölg, N., Nosenko, G., Nuth, C., Pope, A., Racoviteanu, A., Rastner, P., Raup, B., Scharrer, K., Steffen, S., Winsvold, S., 2013. On the accuracy of glacier outlines derived from remote-sensing data. Annals of Glaciology 54 (63).

Paul, F., Huggel, C., Kääb, A., 2004. Combining satellite multispectral image data and a digital elevation model for mapping debris-covered glaciers. Remote Sensing of Environment $89,510-518$.

Racoviteanu, A., Paul, F., Raup, B., Khalsa, S., Armstrong, R., 2009. Challenges and recommendations in mapping of glacier parameters from space: results of the 2008 Global Land Ice Measurements from Space (GLIMS) workshop. Annals of Glaciology 50 (53), $53-69$.

Rotschky, G., Holmlund, P., Isaksson, E., Mulvaney, R., Oerter, H., Broeke, M. V. D., Winther, J.-G., 2007. A new surface accumulation map for western dronning maud land, antarctica, from interpolation of point measurements. Journal of Glaciology 53 (182), 385398. 
Saintenoy, A., Friedt, J.-M., Booth, A. D., Tolle, F., Bernard, É., Laffly, D., Marlin, C., Griselin, M., 2013. Deriving ice thickness, glacier volume and bedrock morphology of the Austre Lovénbreen (Svalbard) using ground-penetrating radar. Near Surface Geophysics $11(2), 253-261$.

Scherler, D., Bookhagen, B., Strecker, M., March 2011. Spatially variable response of himalayan glaciers to climate change affected by debris cover. Nature geoscience 4, 156-159.

Serra, J., 1987. Comments on "geostatistics: Models and tools for the earth sciences". Mathematical Geology 19 (4), 349-355.

Vieli, A., Jania, J., Kolondra, L., 2002. The retreat of a tidewater glacier: observations and model calculations on Hansbreen, Spitsbergen. Journal of Glaciology 48 (163). 


\section{List of Figures}

1 Geographical location of the Austre Lovénbreen, on the west coast of Spitsbergen, $79^{\circ}$ N. . . . . . . . . . . . . . . . .

2 In red: the snout position extracted from digital image processing on a satellite FORMOSAT image acquired on July 31, 2008, geometrically corrected using the ground control points (in yellow). In green, the GPS track recorded end of September, 2008, as an operator walks eastward along the glacier snout. In brown, the GPS track recorded walking westward several hours later. . . . .

3 a) DEM of the glacier basin, b) hillshade analysis emphasizing slope angle change, and c) slope angles over the glacier basin. . . . . . . . . . . . .

4 Upper panel: rimaye as seen on a field picture (2010). Lower panel: rimaye as observed on an aerial photography of the same location (1990). The azimutal projection of both images exhibits a distance of less than 5 meters between rimaye positions. . . . . . . . . . . . . . . . . . .

Position of the 6 tracks along which GPR measurements were gathered to assess the glacier limit position. Each measurement path is oriented orthogonal to the glacier boundary as estimated from color change on a summer satellite picture (solid line). The dashed line lies along the 2010 Equilibrium Limit Altitude (ELA). Bottom: topography corrected traces gathered using GPR on the west-east transect. Notice the blurred interface on the western-most cirque, interpreted as avalanche or rock debris in the ice scattering the electromagnetic signal which is then prevented from reaching the bedrock interface, while the bedrock exhibits a sharp interface on the eastern cirque. The total transect length (west to east, C-D) is $3120 \mathrm{~m}$. The top-profile (E-F) was collected near the snout in September 2012 as the snow layer was thin enough for the rock debris-glacier interface to still be visible. In the latter radargram, dark squares indicate bedieres which were crossed while acquiring the traces.

6 Picture following a measurement along a track linking point A (on the glacier flat surface) and point B (on the slope, near a visible solid rock outcrop) orthogonal to the visually identified glacier boundary (dashed line). Points A and $\mathrm{B}$ are also shown next to profile 2 on Fig. 5. . . . . . . . . . . . 
7 Radargrams acquired on five of the test sites, corresponding from top to bottom to the sites numbered 1 to 5 on Fig. 5. The ice-rock interface are visible as the measurement starts over the glacier area at depths ranging from 50 to $60 \mathrm{~m}$, and reaches the surface at a location marked by the vertical solid lines. Two limits based on sub-surface features are actually selected: intersection of the extrapolated bedrock interface with the surface (furthest to the right) or loss of the interface on the radargrams. The discrepancy with the position of the boundary identified visually as the limit between dark (rock covered) and light (ice/snow covered) areas on aerial images is emphasized by representing this limit as the vertical dashed lines. The bediere on profile 3 (central panel) is visible as a series of strong scatterers from position 400 to $475 \mathrm{~m}$. 1) Slattofjellet, 2) Haavimbfjellet westward, 3) Haavimbfjellet southward, 4) Grönlietoppen westward, 5) soutward exposed ridge . . . . . . . . . .

8 Position of the various glacier limits as a function of analysis method, whether from colorimetric analysis of satellite images (A), hillshade (slope steepness gradient) analysis (B), GPS mapping while walking at the glacier limit (C), and GPR bedrock interface reaching the surface (D). Bottom-right: multiple accumulation layers of rock debris fallen from the slopes are visible over the ice on a picture taken in September, while some of the ice connected to the glacier is still visible on the lower part of the slopes. Both topography lines on the top graphs are derived from cross-sections along the GPR tracks of a DEM made by combining stereo aerial-photography derived altitude measurements on the slopes and our own 2009 dual-frequency GPS measurements for the glacier covered area. . . . . . . . . . . . . . . . . .

9 Interpretation of the radargrams: the slopes, observed as rock covered areas on aerial and satellite images, exhibit an ice-rock interface in the continuity of the glacier ice-rock boundary when probed using a GPR. Since a $100 \mathrm{MHz}$ GPR is unable to observe interfaces within the first meter from the surface, the observed radargrams are interpreted as a thin $(<1 \mathrm{~m}$ thick) rock layer coating an underlying ice mass extending below the visible slope boundary as defined by the rock slides observed visually, and reaching the underlying solid rock in continuity of the glacier bedrock. . . . . . . . . . . . . . 


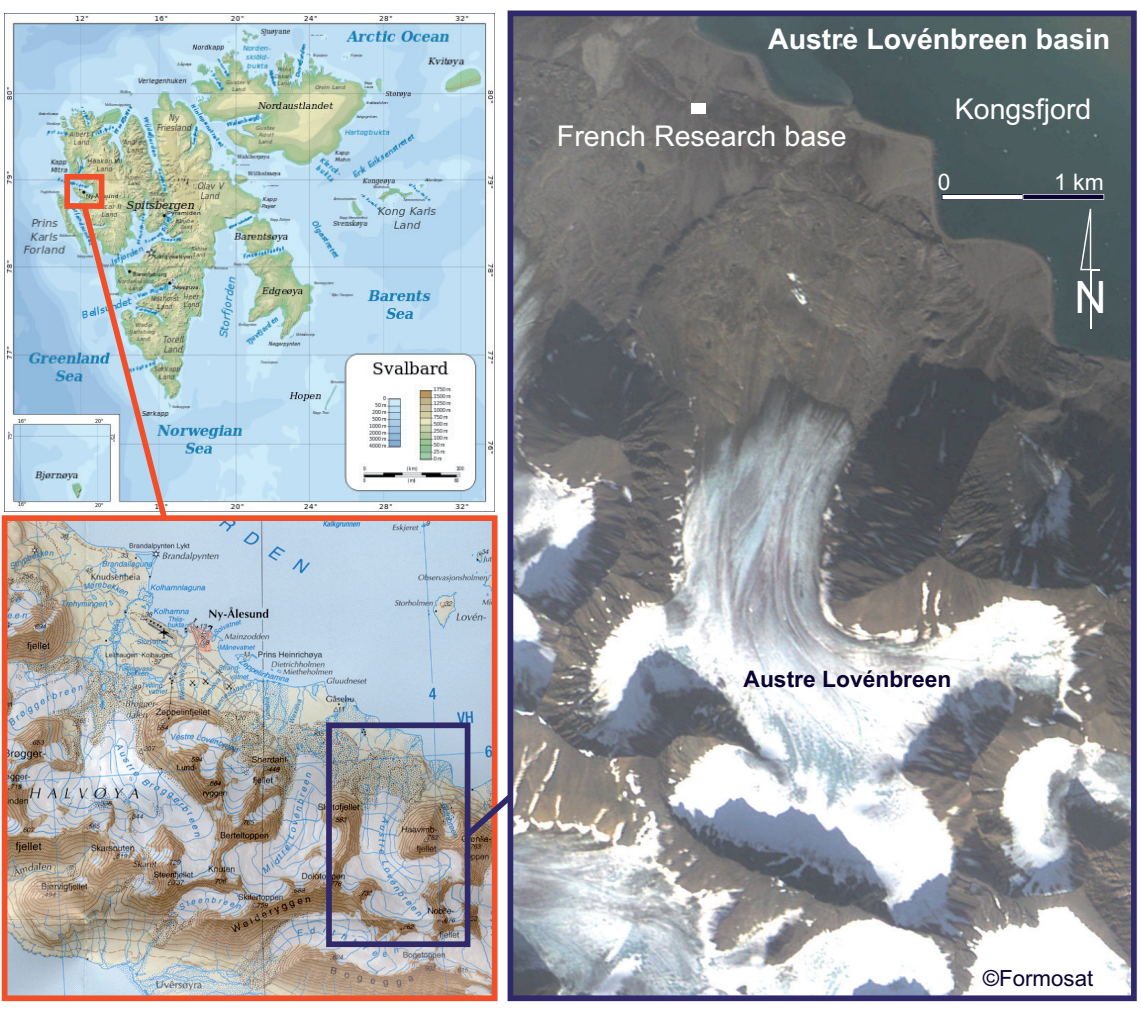

Fig. 1: Geographical location of the Austre Lovénbreen, on the west coast of Spitsbergen, $79^{\circ} \mathrm{N}$. 


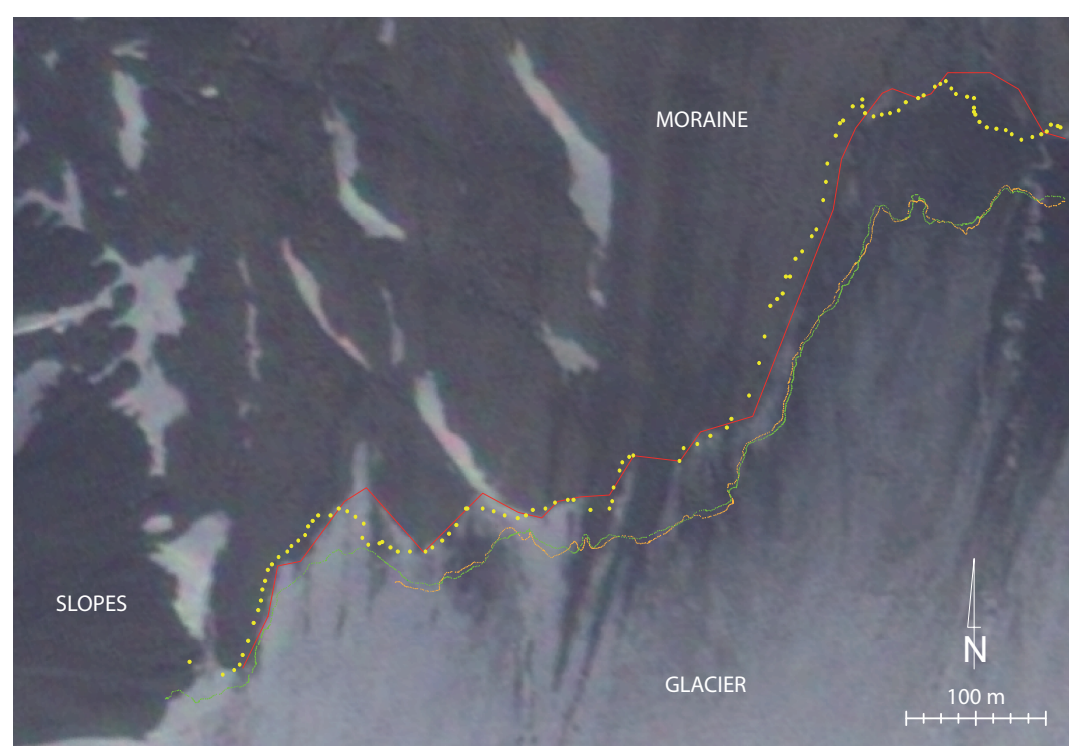

Fig. 2: In red: the snout position extracted from digital image processing on a satellite FORMOSAT image acquired on July 31, 2008, geometrically corrected using the ground control points (in yellow). In green, the GPS track recorded end of September, 2008, as an operator walks eastward along the glacier snout. In brown, the GPS track recorded walking westward several hours later. 

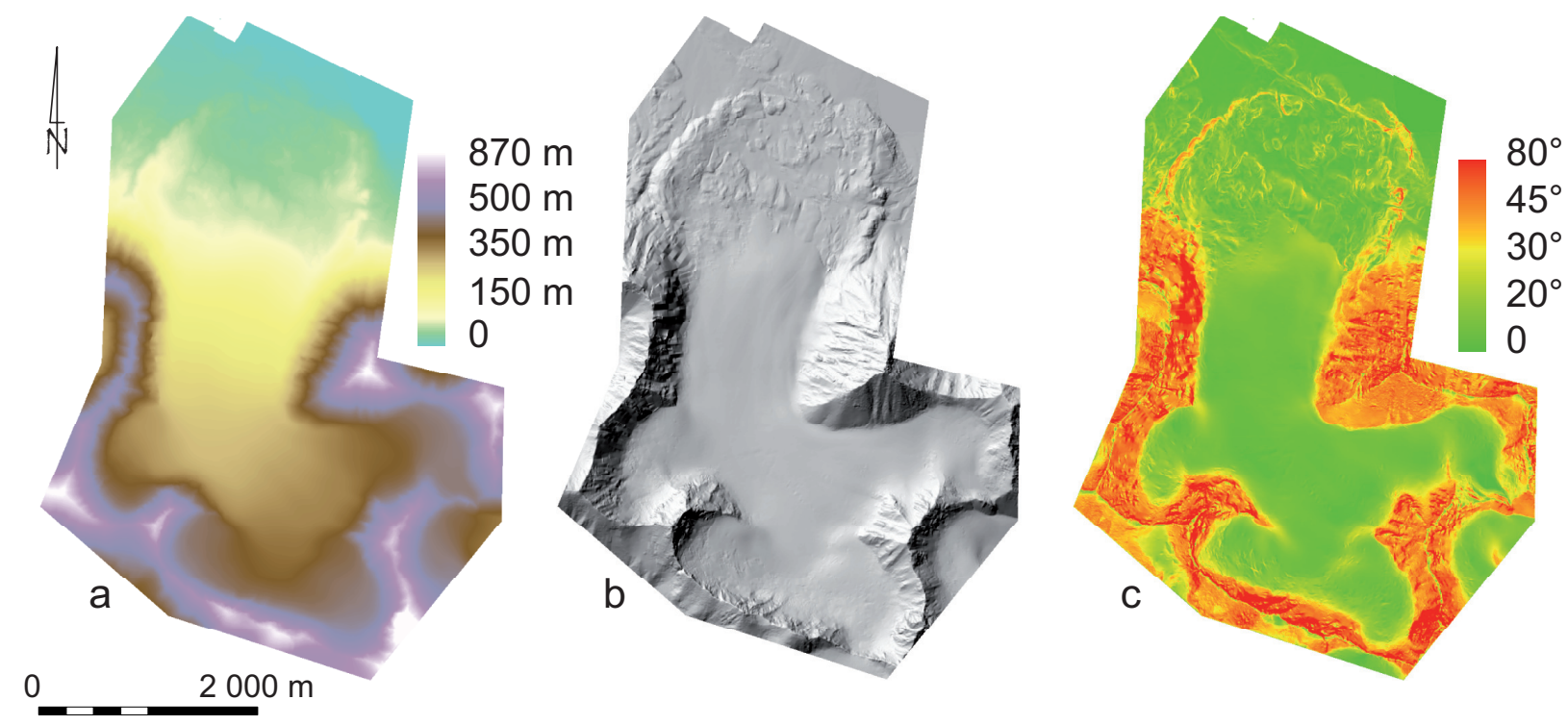

Fig. 3: a) DEM of the glacier basin, b) hillshade analysis emphasizing slope angle change, and c) slope angles over the glacier basin. 

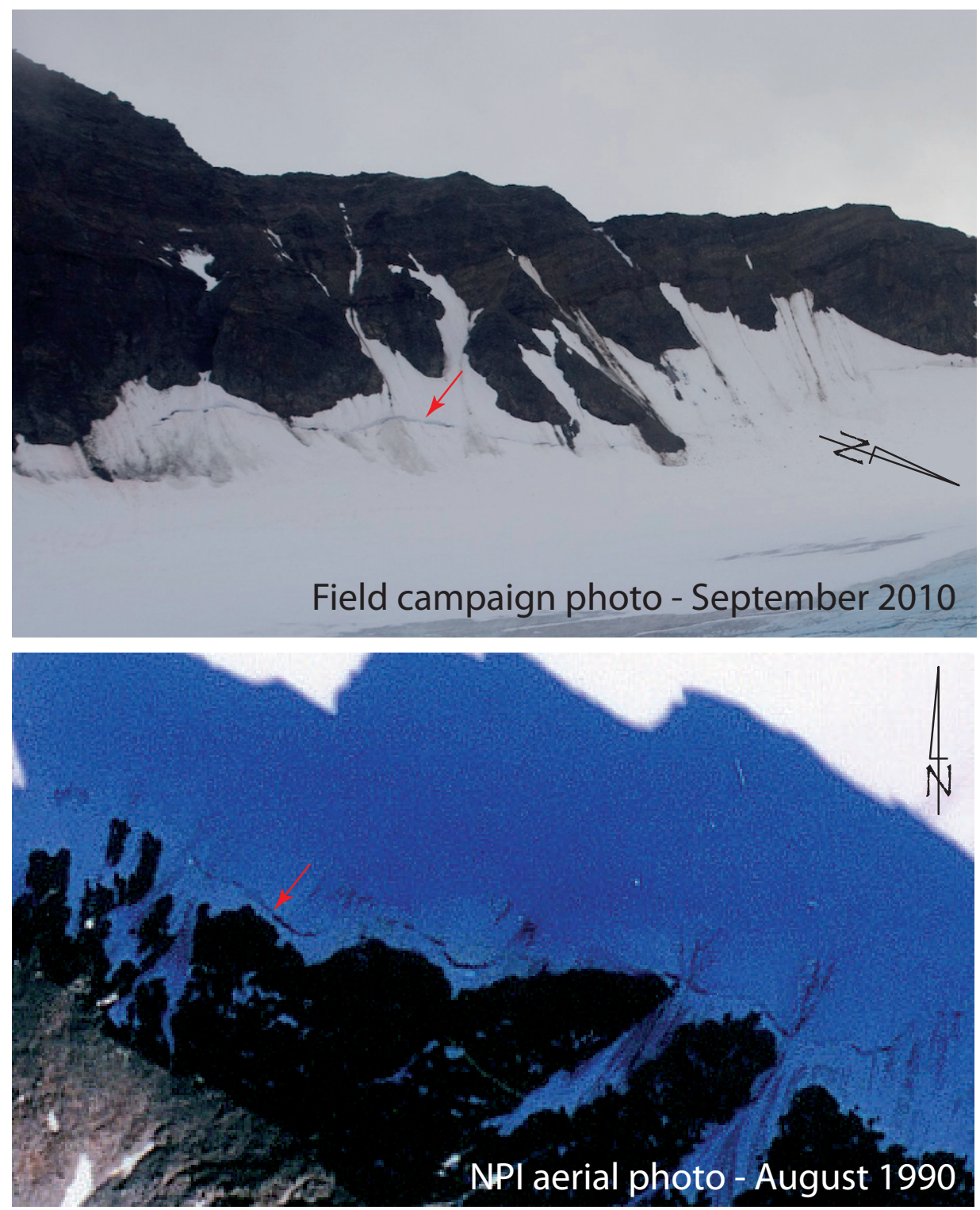

Fig. 4: Upper panel: rimaye as seen on a field picture (2010). Lower panel: rimaye as observed on an aerial photography of the same location (1990). The azimutal projection of both images exhibits a distance of less than 5 meters between rimaye positions. 

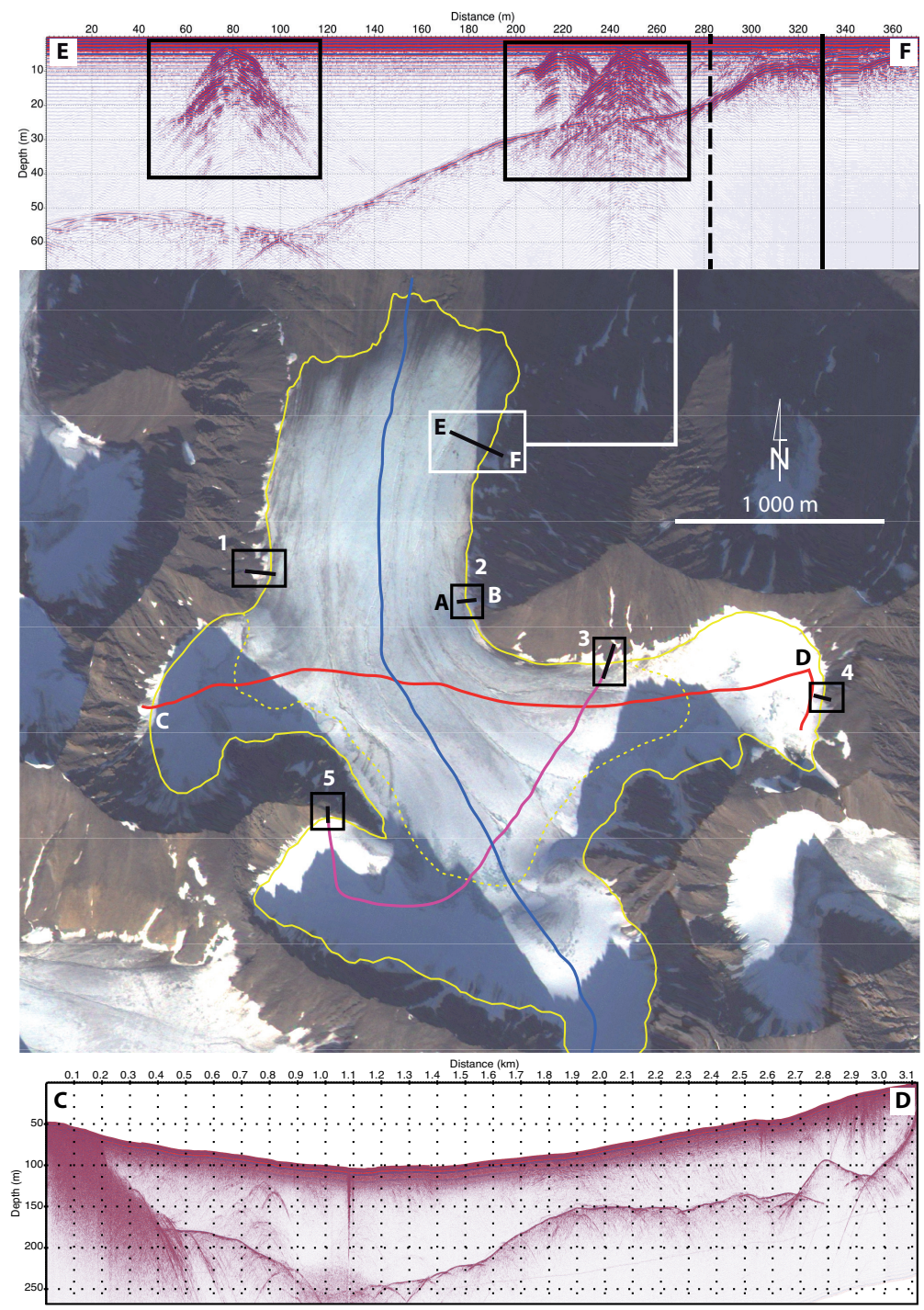

Fig. 5: Position of the 6 tracks along which GPR measurements were gathered to assess the glacier limit position. Each measurement path is oriented orthogonal to the glacier boundary as estimated from color change on a summer satellite picture (solid line). The dashed line lies along the 2010 Equilibrium Limit Altitude (ELA). Bottom: topography corrected traces gathered using GPR on the west-east transect. Notice the blurred interface on the western-most cirque, interpreted as avalanche or rock debris in the ice scattering the electromagnetic signal which is then prevented from reaching the bedrock interface, while the bedrock exhibits a sharp interface on the eastern cirque. The total transect length (west to east, C-D) is $3120 \mathrm{~m}$. The top-profile (E-F) was collected near the snout in September 2012 as the snow layer was thin enough for the rock debris-glacier interface to still be visible. In the latter radargram, dark squares indicate bedieres which were crossed while acquiring the traces. 


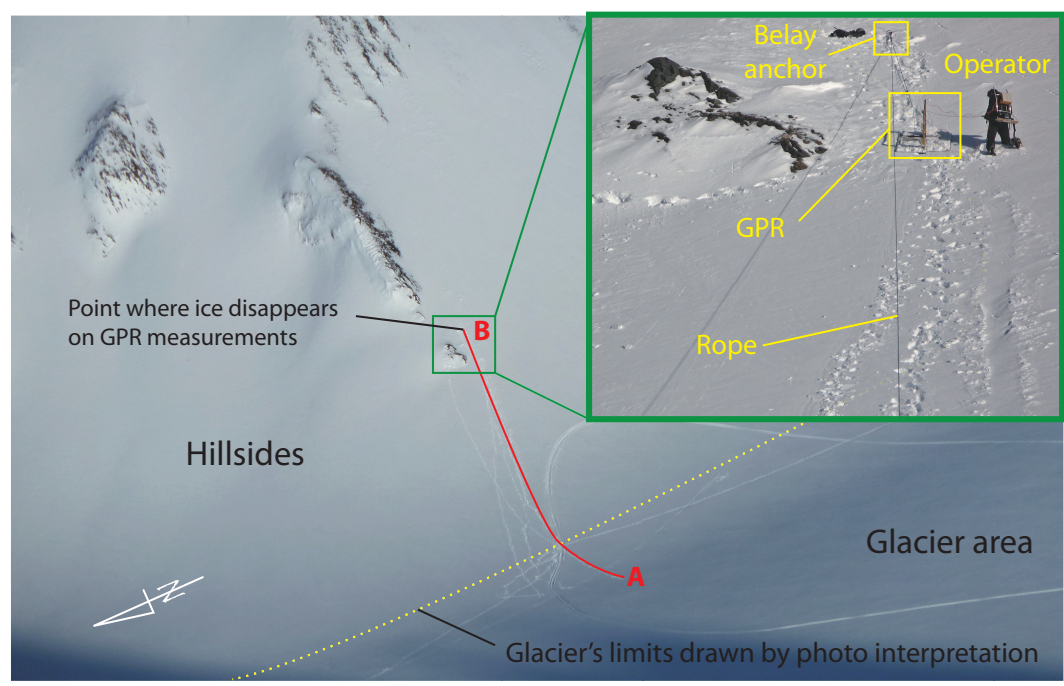

Fig. 6: Picture following a measurement along a track linking point A (on the glacier flat surface) and point $\mathrm{B}$ (on the slope, near a visible solid rock outcrop) orthogonal to the visually identified glacier boundary (dashed line). Points A and B are also shown next to profile 2 on Fig. 5. 

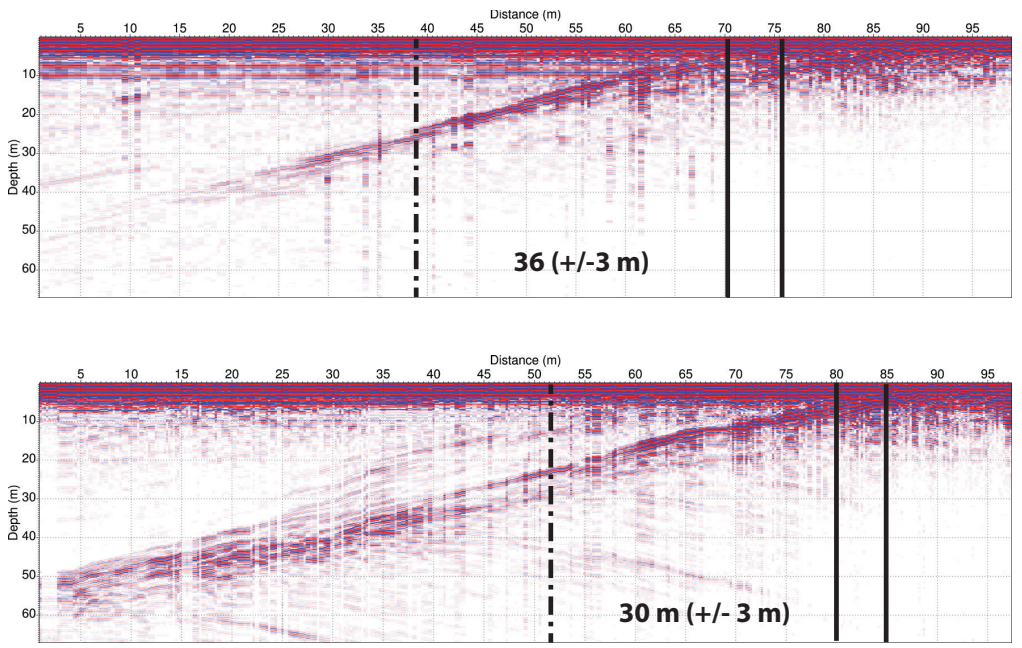

(2)

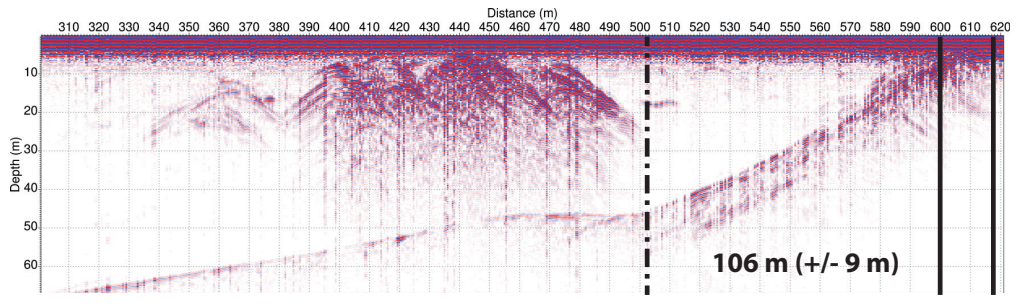

(3)

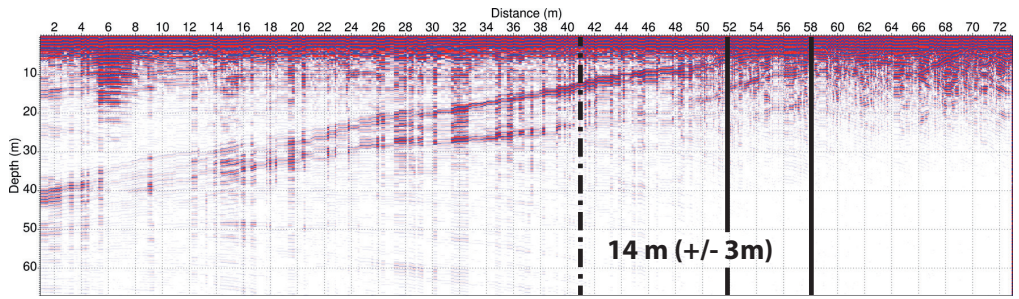

(4)

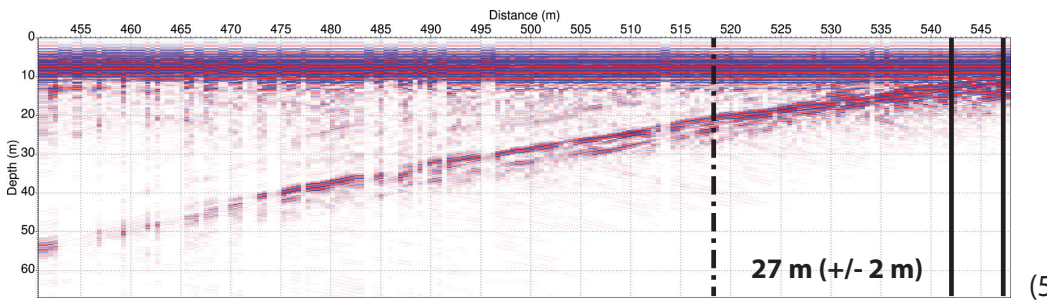

Fig. 7: Radargrams acquired on five of the test sites, corresponding from top to bottom to the sites numbered 1 to 5 on Fig. 5. The ice-rock interface are visible as the measurement starts over the glacier area at depths ranging from 50 to $60 \mathrm{~m}$, and reaches the surface at a location marked by the vertical solid lines. Two limits based on sub-surface features are actually selected: intersection of the extrapolated bedrock interface with the surface (furthest to the right) or loss of the interface on the radargrams. The discrepancy with the position of the boundary identified visually as the limit between dark (rock covered) and light (ice/snow covered) areas on aerial images is emphasized by representing this limit as the vertical dashed lines. The bediere on profile 3 (central panel) is visible as a series of strong scatterers from position 400 to $475 \mathrm{~m}$. 1) Slattofjellet, 2) Haavimbfjellet westward, 3) Haavimbfjellet southward, 4) Grönlietoppen westward, 5) soutward exposed ridge 


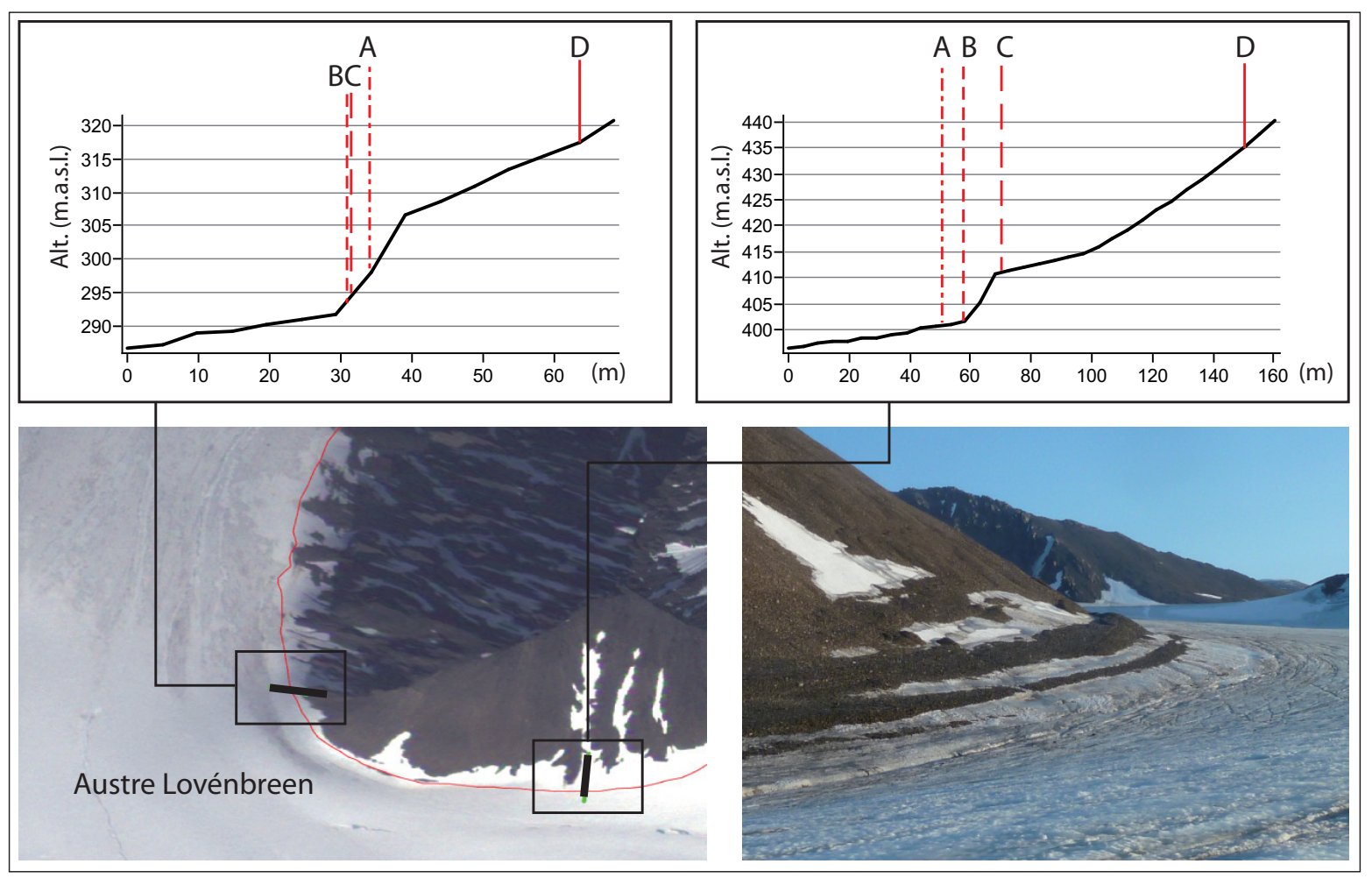

Fig. 8: Position of the various glacier limits as a function of analysis method, whether from colorimetric analysis of satellite images (A), hillshade (slope steepness gradient) analysis (B), GPS mapping while walking at the glacier limit (C), and GPR bedrock interface reaching the surface (D). Bottom-right: multiple accumulation layers of rock debris fallen from the slopes are visible over the ice on a picture taken in September, while some of the ice connected to the glacier is still visible on the lower part of the slopes. Both topography lines on the top graphs are derived from cross-sections along the GPR tracks of a DEM made by combining stereo aerial-photography derived altitude measurements on the slopes and our own 2009 dual-frequency GPS measurements for the glacier covered area. 


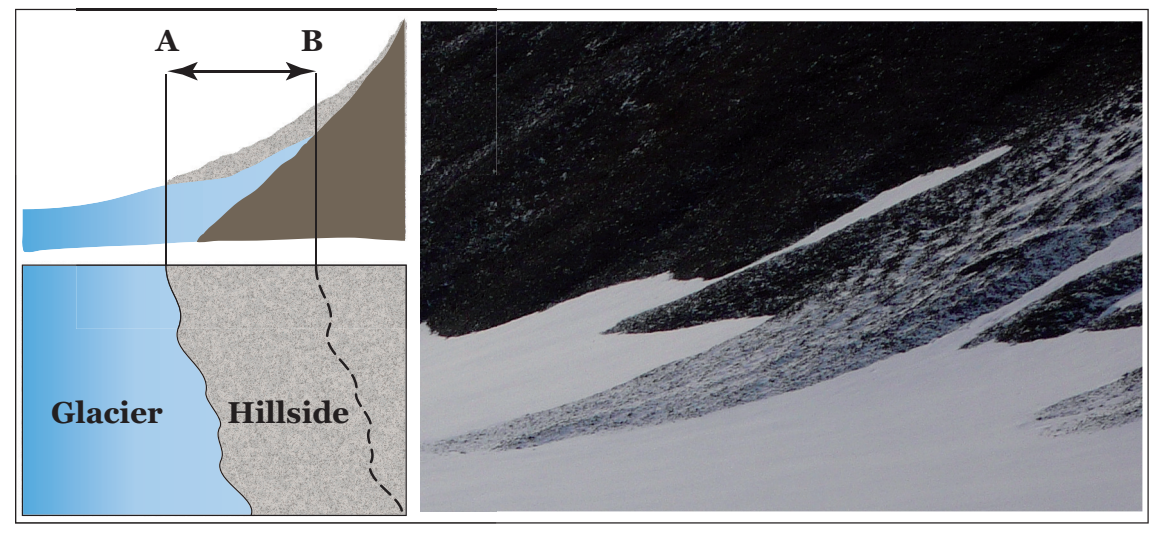

Fig. 9: Interpretation of the radargrams: the slopes, observed as rock covered areas on aerial and satellite images, exhibit an ice-rock interface in the continuity of the glacier ice-rock boundary when probed using a GPR. Since a $100 \mathrm{MHz}$ GPR is unable to observe interfaces within the first meter from the surface, the observed radargrams are interpreted as a thin $(<1 \mathrm{~m}$ thick) rock layer coating an underlying ice mass extending below the visible slope boundary as defined by the rock slides observed visually, and reaching the underlying solid rock in continuity of the glacier bedrock. 